\title{
Serial study of C-reactive protein during infection in leukaemia
}

\author{
PE ROSE, SA JOHNSON,* M MEAKIN, PH MACKIE, $\dagger$ AND J STUART \\ From the Department of Haematology, University of Birmingham, Birmingham B15 2TJ, and the *MRC \\ Leukaemia Unit, Hammersmith Hospital, London W'12 OHS, UK
}

SUMMARY Serum C-reactive protein was studied serially by a 1-hour laser nephelometric assay in 25 patients with leukaemia who developed 34 episodes of infection. The serum level rose above, or by, $100 \mathrm{mg} / \mathrm{l}$ in 29 of the episodes. Serial measurement of this acute-phase reactant was of value in detecting infection in the neutropenic patient and in monitoring the response to antibiotic therapy.

Patients with leukaemia, particularly those who become neutropenic during attempted remission induction of acute myeloid leukaemia, are at considerable risk of infection. Despite the advantages of protective isolation, ${ }^{12}$ prophylactic antibiotic therapy, ${ }^{3} 4$ and empirical antibiotic therapy, ${ }^{5}$ infection is the commonest cause of death. The diagnosis of infection is particularly difficult, moreover, when there are insufficient neutrophils to migrate to a site of infection to cause localising signs, and when previous antibiotic therapy hinders bacteriological isolation. The transfusion of blood, platelets, or granulocytes and the infusion of cytotoxic drugs may also induce pyrexia, thereby mimicking infection.

An earlier study of C-reactive protein (C-RP), using the 18-hour radial immunodiffusion technique, suggested that a serum level of above $100 \mathrm{mg} / \mathrm{l}$ indicated the presence of infection. ${ }^{6}$ Serial measurements of C-RP were carried out in the present study by the 1-hour laser nephelometric assay to determine the value of this rapid technique for detecting infection in leukaemic patients.

\section{Patients and methods}

Twenty-five adult inpatients with leukaemia (11 acute myeloblastic, 4 acute monocytic, 6 chronic granulocytic leukaemia with 5 in blastic crisis, and 4 acute lymphoblastic) were either admitted with infection or subsequently developed evidence of infection. In the majority, the infection was a

†Present address: Department of Haematology, John Radcliffe Hospital, Headington, Oxford OX3 9DU. complication of severe neutropenia. Serum C-RP levels were estimated serially before, during, and after these episodes with an average of 14 estimations per patient. The estimations were performed using a Hyland Laser Nephelometer PDQ ${ }^{\mathrm{TM}}$ (Travenol Laboratories, Thetford) as follows:

DilUENT (pH 7.2)

Disodium hydrogen orthophosphate (anhydrous)

Sodium dihydrogen orthophosphate (hydrated)

Sodium azide

Polyethylene glycol (MW 4000)

Sodium chloride $(0.9 \% \mathrm{w} / \mathrm{v})$ $1.07 \mathrm{~g}$ $0.39 \mathrm{~g}$ $1.0 \mathrm{~g}$ $40.0 \mathrm{~g}$ to 11

ANTISERUM

Nephelometric grade goat anti-human C-RP (Seward Immunostics, London) was diluted $1 / 100$ in the above and filtered through a $0.4 \mu \mathrm{m}$ Nuclepore (Pleasanton, California) polycarbonate membrane filter immediately before use.

\section{STANDARD SERUM}

Human serum of known C-RP concentration (205 $\mathrm{mg} / \mathrm{l})$, as calibrated against our previous reference preparation, ${ }^{6}$ was double-diluted from $1 / 10$ to $1 / 320$ in $0.9 \% \mathrm{w} / \mathrm{v}$ sodium chloride.

\section{STANDARD CURVE}

A standard curve was prepared for each batch of test sera. Diluted antiserum $(1.0 \mathrm{ml})$ was pipetted into each of six Hyland nephelometer cuvettes (Travenol Laboratories, Thetford), $\mathbf{0 . 1} \mathrm{ml}$ of each dilution of the standard was added, and the tube 
contents were mixed by inversion. Six blank tubes were similarly prepared by the addition of $0.1 \mathrm{ml}$ of each dilution of the standard to $1.0 \mathrm{ml}$ volumes of diluent without antiserum. The tubes were left at room temperature for 1 hour, and the nephelometer readings were then plotted arithmetically against concentration.

\section{TEST SERA}

Patient sera were initially diluted $1 / 10$ and $1 / 50$ in $0.9 \% \mathrm{w} / \mathrm{v}$ sodium chloride, and $0.1 \mathrm{ml}$ aliquots were then pipetted into $1.0 \mathrm{ml}$ diluted antiserum, mixed, and left for 1 hour as above. A blank tube was prepared for each test serum. All estimations were performed in duplicate on two successive days by one of us (MM), without access to clinical information, on either fresh or deep-frozen $(-20 \mathrm{C})$ sera. London specimens had thawed during transport to Birmingham and were re-frozen before assay in batches. There was no evidence, from the results of serial specimens, that haemolysis, re-freezing, or the age of the specimen influenced the results. Repeated thawing and freezing did sometimes result in the formation of a precipitate causing high blank values with minor loss of sensitivity. Lipaemic specimens resulted in high blank values which occasionally also reduced the sensitivity of the assay.

\section{Results}

Thirty-four episodes of infection were investigated. A positive blood culture was obtained in 13 episodes (Table 1), and the C-RP level rose to above $100 \mathrm{mg} / \mathrm{l}$ in 10 of these. This rise preceded the date of a positive blood culture by one to four days in three episodes. In one of the three C-RP failures, the peak level reached $93 \mathrm{mg} / \mathrm{l}$ in a patient with a central venous line, a temperature of $39^{\circ} \mathrm{C}$, and a Streptococcus viridans bacteraemia. The C-RP level again

Table 1 Thirteen episodes of infection with positive blood culture

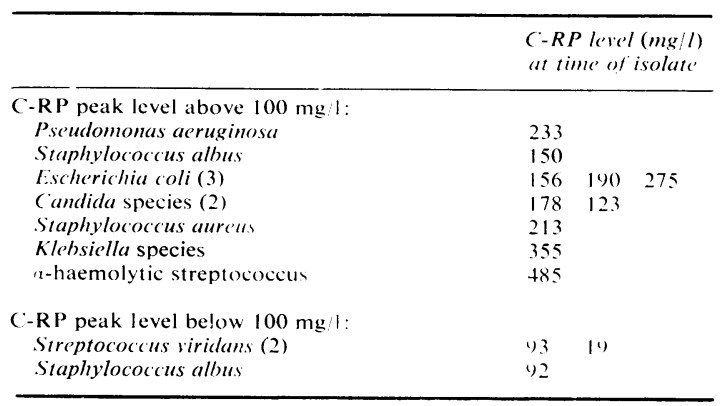

Table 2 Seventeen episodes of infection, other than bacteraemia, confirmed radiologically or bacteriologically.

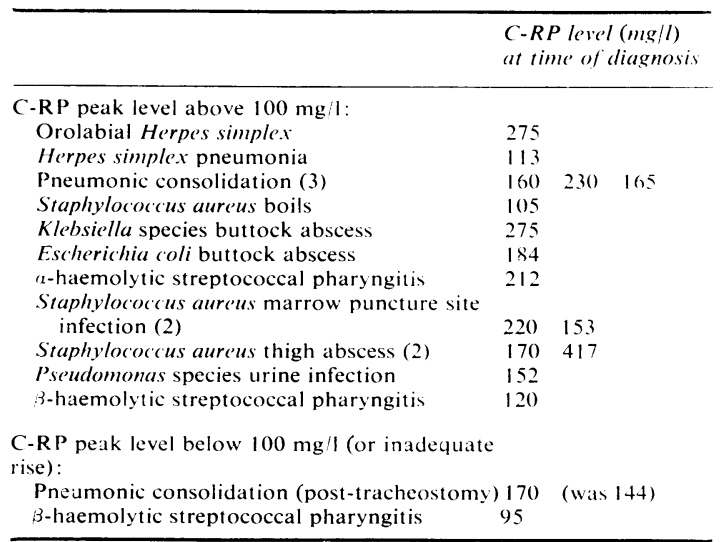

reached only $92 \mathrm{mg} / \mathrm{l}$ in a patient from whom Staphylococcus albus was isolated in three blood cultures taken simultaneously. In the third failure, the blood level did not exceed $19 \mathrm{mg} / \mathrm{l}$ in specimens taken two days before and two days after an isolate of Strep. viridans when the temperature was $40^{\circ} \mathrm{C}$. It is unlikely that the C-RP level both rose to and fell from $100 \mathrm{mg} / \mathrm{l}$ during the four-day interval.

In 17 episodes of infection without detected bacteraemia, the C-RP level rose above $100 \mathrm{mg} / \mathrm{l}$ in 15 and failed to do so in two (Table 2). In nine of these 15 episodes, the C-RP was greater than $100 \mathrm{mg} / \mathrm{I}$ for between one and 14 days before bacteriological or radiological confirmation of infection was obtained. In one failure, the patient had a previously elevated level above $100 \mathrm{mg} / \mathrm{l}$ for the previous 23 days as a consequence of recurrent episodes of arm and thigh cellulitis and also a tracheostomy. The development of left basal pneumonia 24 hours after tracheostomy was associated with a C-RP rise from 144 to $170 \mathrm{mg} / \mathrm{l}$; the previous infection and postoperative acute-phase protein response undoubtedly influenced this poor response to new infection.

Bacteriological confirmation of clinically evident infection was not obtained in four other episodes; in these, a C-RP level above $100 \mathrm{mg} / \mathrm{l}$ was obtained in each case (Table 3 ).

Table 3 Four episodes of infection diagnosed clinically. but without bacteriological isolate

\begin{tabular}{ll}
\hline & $\begin{array}{l}C-R P \text { level (mg/l) } \\
\text { at time of diagnosis }\end{array}$ \\
\hline C-RP peak level above $100 \mathrm{mg} / 1:$ & \\
Cellulitis of hand and arm & 240 \\
Clinical septicaemia with rigors & 184 \\
Balanitis and productive cough & 108 \\
Infected intravenous drip site & 180 \\
\hline
\end{tabular}




\section{Discussion}

This serial study provides additional support to the observation that C-RP levels of above $100 \mathrm{mg} / \mathrm{l}$ are of diagnostic value in leukaemic patients with suspected infection. ${ }^{6}$ We now recommend that blood specimens be taken for assay, or for storage, whenever venepuncture is performed in the neutropenic patient; the stored sera may then be used to provide sequential results if pyrexia subsequently develops. The serial study of C-RP is of considerably greater value in diagnosis, and as a guide to therapy, than single estimations.

Elevation of C-RP did not always occur in parallel with a rise in temperature during episodes of infection. Pyrexia developed first in four episodes, and $a$ rise in C-RP was an earlier indicator of infection in six episodes. A C-RP level greater than $100 \mathrm{mg} / \mathrm{l}$ in an apyrexial patient therefore justifies intensive search for a focus of infection. The results shown in Fig. 1 were obtained from a leukaemic patient who developed, on day 13, a thigh abscess from which Streptococcus faecalis and Staphylococcus aureus were isolated. Despite absence of pyrexia, the C-RP had been persistently greater than $100 \mathrm{mg} / \mathrm{l}$. In this example, the C-RP rise not only occurred in the absence of a temperature rise but also preceded clinical presentation of the infected lesion. Earlier antibiotic treatment could have been administered if the C-RP level had been used as an indicator of infection.

The clinical value of serial C-RP estimations is further illustrated in Figure 2. This thrombocytopenic patient presented on day 0 with a swollen, tender thigh, which was initially diagnosed as an expanding haematoma. In a study of 50 bleeding episodes (12 haematomas and 38 haemarthroses) in patients with inherited bleeding disorders, however, the C-RP failed to reach $100 \mathrm{mg} / \mathrm{l}$ in any case. The elevated C-RP level, reaching $440 \mathrm{mg} / \mathrm{l}$ in

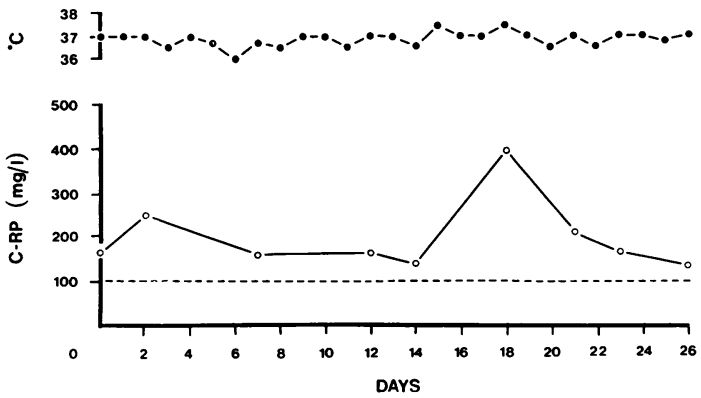

Fig. 1 Normal temperature (O) but elevated $C-R P(O)$ values in a patient in whom clinical signs of a thigh abscess were not apparent until day 13.

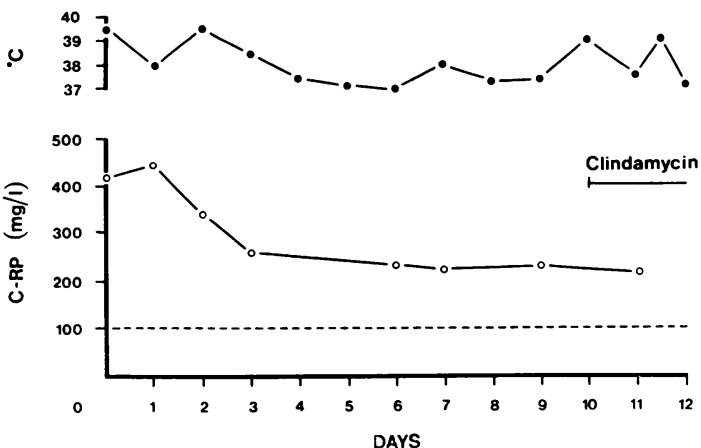

Fig. 2 Elevated $C-R P(O)$ values in a pyrexial (O) patient with a swollen thigh which could not be diagnosed as an abscess until day 10.

this patient, therefore indicated an infective cause for the swollen thigh. The swelling subsequently localised (day 10) to form a large abscess from which Staph. aureus was isolated and which responded to clindamycin.

A further rise in C-RP level, when already greater than $100 \mathrm{mg} / \mathrm{l}$, may reflect the development of new infection. Two patients who developed bacteraemia, and another with a thigh abscess, already had C-RP levels above $150 \mathrm{mg} / \mathrm{l}$ as a consequence of previous infection. A further rise of at least $100 \mathrm{mg} / \mathrm{l}$ occurred in all three in parallel with a new infection. The patient in Fig. 3 with alpha-haemolytic streptococcal pharyngitis on day 2 was not treated, despite neutropenia, in view of apparent spontaneous resolution. She was readmitted on day 14 , four days after discharge, having developed an alphahaemolytic streptococcal septicaemia. The C-RP level during the first admission had been greater than

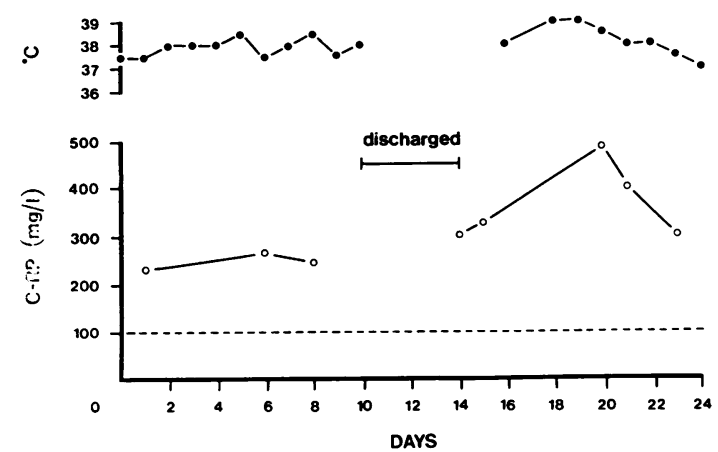

Fig. 3 Serial temperature $(O)$ and elevated $C-R P(O)$ values during two admissions in a patient who developed a-haemolytic streptococcal bacteraemia, diagnosed on day 19, after previous pharyngeal infection by the same organism diagnosed on day 2. 

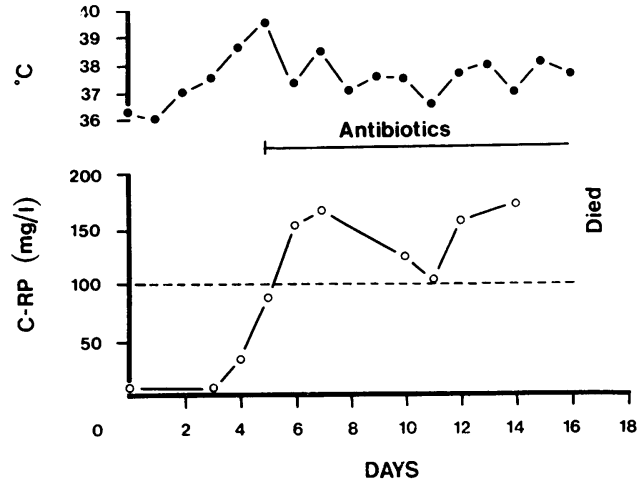

Fig. 4 Serial temperature $(O)$ and $C-R P(\bigcirc)$ values in a patient with chest wall cellulitis (day 5) followed by an incomplete response to antibiotics and a subsequent Klebsiella aerogenes bacteraemia (day 16).

$200 \mathrm{mg} / \mathrm{l}$ and rose to $480 \mathrm{mg} / \mathrm{l}$ with the development of septicaemia on readmission.

In other patients, the failure of a high C-RP level to fall below $100 \mathrm{mg} / \mathrm{l}$, or indeed a continuing rise, indicated an inadequate response to antibiotics and a poor prognosis. The patient in Fig. 4 was started on antibiotics on day 5 , having developed an infected sternal aspirate site with subsequent spreading cellulitis. The initial good response to antibiotic treatment was reflected by the falling C-RP values. The C-RP level, however, again rose together with the isolation of Klebsiella aerogenes from blood cultures on day 16. The C-RP level should, therefore, continue to be studied serially even when greater than $100 \mathrm{mg} / \mathrm{l}$ since a failure to fall, or further elevation, can indicate a need for the antibiotics to be changed or for a granulocyte transfusion to be added.

Although we have observed two patients with an extensive maculopurpuric rash, as a consequence of drug hypersensitivity, who developed a false-positive rise in C-RP level to above $100 \mathrm{mg} / 1$, we have not observed a rise of this magnitude after the infusion of red cells, platelets, granulocytes, or cytotoxics even in the presence of a pyrexial reaction. On three occasions patients with pyrexia after cytotoxic infusion were given antibiotics unnecessarily since subsequent testing of stored sera showed no rise in C-RP level to above $100 \mathrm{mg} / \mathrm{l}$ and there was no clinical or microbiological evidence of infection.

Patients with active rheumatoid arthritis occasionally show a disproportionately low C-RP level and may be 'poor responders' (RA Crockson, personal communication). Two of our leukaemic patients failed to reach a C-RP level of $100 \mathrm{mg} / \mathrm{l}$ in each of two infective episodes, and one remained below $50 \mathrm{mg} / 1$ during a Strep. viridans bacteraemia. 'Poor responders' probably exist in diseases other than rheumatoid arthritis and constitute a group in whom C-RP is an inadequate test of infection. Such patients, however, are comparatively uncommon.

Infection should therefore be suspected in the leukaemic patient whenever the serum C-RP level already exceeds $100 \mathrm{mg} / \mathrm{l}$ on admission, subsequently rises above $100 \mathrm{mg} / \mathrm{l}$, or increases further by $100 \mathrm{mg} / \mathrm{l}$. The 1-hour laser nephelometric assay, compared with the 18-hour radial immunodiffusion technique, is sufficiently rapid to allow a clinical decision to be delayed until the assay result is available. Serial specimens should continue to be taken after antibiotic therapy has started in order to monitor the therapeutic response. A prospective trial is required to determine whether a fall in C-RP level to below $100 \mathrm{mg} / \mathrm{l}$ indicates that antibiotics can safely be stopped, and this is now in progress.

We are indebted to the Leukaemia Research Fund for financial support; to Professor DAG Galton, Dr JM Goldman, and Dr D Catovsky for allowing access to their patients; to Mr AJ Davies and Mr PC Stone for development of the assay; and to Mr RA Crockson for the C-RP standard serum and for much helpful advice.

\section{References}

1 Jameson B, Gamble DR, Lynch J, Kay HEM. Five-year analysis of protective isolation. Lancet 1971;1:1034-40.

${ }^{2}$ Yates JW, Holland JF. A controlled study of isolation and endogenous microbial suppression in acute myelocytic leukemia patients. Cancer 1973;32:1490-8.

${ }^{3}$ Storring RA, Jameson B, McElwain TJ, Wiltshaw E, Spiers ASD, Gaya H. Oral non-absorbed antibiotics prevent infection in acute non-lymphoblastic leukaemia Lancet $1977 ; 2: 837-40$.

${ }^{4}$ Enno A, Catovsky D, Darrell J, Goldman JM, Hows J, Galton DAG. Co-trimoxazole for prevention of infection in acute leukaemia. Lancet 1978;2:395-7.

${ }^{5}$ EORTC International Antimicrobial Therapy Project Group. Three antibiotic regimens in the treatment of infection in febrile granulocytopenic patients with cancer. $J$ Infect Dis 1978;137:14-29.

6 Mackie PH, Crockson RA, Stuart J. C-reactive protein for rapid diagnosis of infection in leukaemia. J Clin Pathol 1979;32:1253-6.

Requests for reprints to: Professor J Stuart, Department of Haematology, Medical School, Vincent Drive, Birmingham B15 2TJ. 